\title{
Assessing Working Memory via N-Back Task in Euthymic Bipolar I Disorder Patients: A Review of Functional Magnetic Resonance Imaging Studies
}

\author{
Laura Cremaschi $^{\mathrm{a}}$ Beatrice Penzo ${ }^{\mathrm{a}}$ Mariacarlotta Palazzo ${ }^{\mathrm{a}}$ Cristina Dobrea ${ }^{\mathrm{a}}$ \\ Marta Cristoffanini ${ }^{b}$ Bernardo Dell'Osso $^{a} \quad$ A. Carlo Altamura ${ }^{a}$ \\ Departments of a Psychiatry and ' ${ }^{b}$ Neuroradiology, Fondazione IRCCS Ca' Granda, Ospedale Maggiore Policlinico, \\ University of Milan, Milan, Italy
}

\begin{abstract}
Key Words
Bipolar I disorder · Euthymia · Functional magnetic resonance imaging $\cdot$ Working memory $\cdot \mathrm{N}$-back task
\end{abstract}

\begin{abstract}
Bipolar disorder (BD) is a chronic and highly disabling mood disorder, associated with the highest suicide rate among psychiatric disorders. Even though neurobiological bases of $\mathrm{BD}$ have still to be further elucidated, recent neuroimaging studies provided compelling evidence about functional correlates of cognitive deficits in BD patients, with working memory (WM) impairment being one of the most commonly reported findings. Such dysfunctions are likely to persist beyond acute phases of the illness, so they qualify as endophenotypic markers for the disorder. This review sought to synthesize, through a MEDLINE search up to December 2012, published functional magnetic resonance imaging (fMRI) studies on WM networks, conducted through $\mathrm{N}$-back task in euthymic BD I patients and including a control comparison group. Eight studies meeting the search criteria were identified. Despite heterogeneity across findings, particularly in relation to task performance (i.e. accuracy and reaction time), most studies reported a loss of connectivity in BD patients' prefrontal networks, traditionally involved in WM, as well as patterns of abnormal activation in the dorso/ventrolateral prefrontal cortex, other prefrontal areas and the pari-
\end{abstract}

etal and temporal cortex. These findings suggest the involvement of intact secondary systems in order to overcome lack of integrity across WM circuits in BD patients. Further investigation in the field is warranted.

Copyright $\odot 2013$ S. Karger AG, Basel

\section{Introduction}

Bipolar disorder $(\mathrm{BD})$ is a chronic and recurrent mood disorder, included among the leading worldwide causes of disability and associated with significant morbidity and suicide rates $[1,2]$. In addition to mood instability, another major symptom domain is represented by neurocognitive impairment, observed across a wide range of functions, including executive functions, memory, working memory (WM), verbal learning, speed of processing information, visual memory and sustained attention [3, 4]. Indeed, many of the aforementioned cognitive deficits were found to persist during euthymic phases [5-8], often being responsible for partial interepisodic functional recovery $[9,10]$. For such reasons, a growing body of evidence suggests that they may be considered as trait biomarkers, rather than as state variables of illness [11, 12].

Dysfunction in WM processing, in particular, has been a consistently reported finding in euthymic BD patients $[13,14]$. WM specifically refers to a set of processes aimed

\section{KARGER}

E-Mail karger@karger.com

www.karger.com/nps
(C) 2013 S. Karger AG, Basel

0302-282X/13/0682-0063\$38.00/0
Dr. Bernardo Dell'Osso, MD

Department of Psychiatry, University of Milan

Fondazione IRCCS Cà Granda, Ospedale Maggiore Policlinico

via Francesco Sforza 35, IT-20122 Milano (Italy)

E-Mail bernardo.dellosso@ policlinico.mi.it 
at 'on-line' holding and manipulating acquired information, allowing the subject to properly interact with any life context in the absence of external cues [15].

Even though neurobiological correlates of WM have not yet been clearly elucidated, several strands of evidence from combined neuropsychological and functional neuroimaging studies converge to consider WM impairment as a candidate endophenotype for BD [16]. Among suitable endophenotypes for $\mathrm{BD}$, however, the importance of epigenetic transformations and developmental factors in the expression of psychiatric phenotypes needs to be taken into account [17]. Therefore, assessing WM in euthymic patients might overcome such transformation and satisfy the 'state independence' criterion, indicated by some authors as crucial to achieve for candidate endophenotypes [18].

The N-back task is one of the most extensively used paradigms for the assessment of WM [19], investigating neural activation elicited by an increasing cognitive load. During task performance, participants are required to monitor a series of stimuli and to indicate whenever the stimulus currently presented is the same as what appeared in a previous set, typically 1, 2 or 3 times (i.e. 1-, 2- and 3 -back), so that increasing memory load is determined by increasing the number of items the subject has to keep in mind [20]. Available data from neuroimaging studies assessing neural response in $\mathrm{BD}$ patients performing an $\mathrm{N}$ back task are quite heterogeneous. Some reveal differences in terms of performance versus healthy controls, whereas others present a mixed picture of hyperactivation and hypoactivation in the specific brain regions traditionally involved in WM circuits including the dorsolateral prefrontal cortex (DLPFC), the ventrolateral prefrontal cortex (VLPFC) as well as the parietal and temporal cortices [21-24].

In the light of an increasing number of publications in this specific field, this review was aimed to synthesize current evidence from published functional magnetic resonance imaging (fMRI) studies assessing WM by means of an N-back task in euthymic BD I patients. Potential implications and future research directions in this field are also discussed.

\section{Methods}

A literature search was conducted on the PubMed database, using systematic combinations of the following keywords: 'functional magnetic resonance imaging' or 'fMRI', 'bipolar disorder', 'euthymia', 'working memory' or 'WM' and 'N-back task'.

Studies were considered for inclusion when they fulfilled the following criteria: (1) use of fMRI, (2) assessment of WM through
N-back task, (3) comparing a sample of subjects with BD I in the euthymic phase with a group of healthy controls, (4) published in English and (5) published up to December 2012. No a priori search chronological limit was established.

As this review focused on the use of the N-back task in euthymic BD patients, studies taxing WM with different tasks (i.e. emotional N-back task, Digit Span) were deliberately excluded from the search, as well as those exclusively investigating mood states other than euthymia.

\section{Results}

Taken as a whole, we identified 8 studies suitable for inclusion in our review. Originally, 12 were identified; however, 4 of these were excluded for they did not specifically use the N-back task. When tasks other than $\mathrm{N}$ back (the Sternberg task or the IOWA Gambling task) were included in the studies investigating $\mathrm{WM}$ via $\mathrm{N}$ back, these were briefly mentioned for completeness.

All the selected reports were case-control studies, comparing euthymic BD I patients with matched healthy controls; 2 included a further comparison group of firstdegree relatives of subjects with BD and 1 added a third comparison group of schizophrenic patients. The years of publication were 2004-2011.

Study samples ranged from a minimum of 7 to a maximum of 36 euthymic patients, with an exclusive diagnosis of BD I, ascertained by the Structured Clinical Interview for DSM-IV [25], including comparison samples of healthy volunteers ranging from 7 to 38 subjects. Comorbidities with other psychiatric disorders were excluded in 3 studies, were not specified in 2 reports, and were limited to substance abuse as an exclusion criterion in another study. Only 1 study included alcohol abuse and panic disorder as psychiatric comorbidities. Recruited patients were mostly on standard and stable pharmacological treatment including mood stabilizers, anticonvulsants, antipsychotics and antidepressants and only a few subjects were not on any medication.

Table 1 summarizes the main findings of the reviewed studies, first reporting behavioral data (accuracy and reaction times) and then the neurofunctional findings.

We review each study, reported in chronological order, in detail, providing data of behavioral performances (i.e. accuracy and reaction times) as well as results related to neural activation patterns.

In 2004, Adler et al. [21] performed a 3-tesla (T) fMRI study in 15 euthymic BD patients and in 15 age- and gender-matched controls, assessing WM through a 2-back task alternating with a 0-back control/attention task. Pa- 
Table 1. Main findings from fMRI studies with N-back task assessing WM in euthymic bipolar patients

\begin{tabular}{|c|c|c|c|c|c|}
\hline Authors & Patients & $\begin{array}{l}\text { Controls and } \\
\text { comparison groups }\end{array}$ & Task & fMRI & Findings (behavioral data and neural activation) \\
\hline $\begin{array}{l}\text { Adler et al., } 2004 \\
\text { [21] }\end{array}$ & $\begin{array}{l}15 \mathrm{BD} \text { I } \\
\text { euthymic patients } \\
\text { mean age } \pm \text { DS: } 29 \pm 9\end{array}$ & 15 controls & 0 -, 2-back & $3.0 \mathrm{~T}$ & $\begin{array}{l}\text { BD vs. controls: } \\
\downarrow \text { accuracy, no differences in reaction times; } \\
\uparrow \text { activation in } \\
\text { frontopolar PFC } \\
\text { temporal cortex } \\
\text { posterior parietal cortex } \\
\text { basal ganglia, thalamus }\end{array}$ \\
\hline $\begin{array}{l}\text { Monks et al., } 2004 \\
{[22]}\end{array}$ & $\begin{array}{l}12 \text { BD I euthymic } \\
\text { patients } \\
\text { mean age } \pm \text { DS: } \\
45.83 \pm 2.76\end{array}$ & 12 controls & $\begin{array}{l}\text { 2-back, Sternberg } \\
\text { paradigm }\end{array}$ & $1.5 \mathrm{~T}$ & $\begin{array}{l}\text { BD vs. controls: } \\
\text { no differences in accuracy and reaction times; } \\
\downarrow \text { activation in } \\
\text { left frontal lobe } \\
\text { right middle temporal gyrus } \\
\text { cuneus/precuneus } \\
\text { cerebellum } \\
\uparrow \text { activation in } \\
\text { left precentral cortex } \\
\text { right medial frontal gyri } \\
\text { left supramarginal gyri }\end{array}$ \\
\hline $\begin{array}{l}\text { Frangou et al., } 2008 \\
{[23]}\end{array}$ & $\begin{array}{l}7 \mathrm{BD} \text { I } \\
\text { euthymic patients } \\
\text { mean age } \pm \mathrm{DS}: \\
37 \pm 5.88\end{array}$ & 7 controls & $\begin{array}{l}\text { 1-, 2-, 3-back, } \\
\text { Iowa Gambling task }\end{array}$ & $1.5 \mathrm{~T}$ & $\begin{array}{l}\text { BD vs. controls: } \\
\text { no differences in accuracy and reaction times; } \\
\downarrow \text { activation in VPFC and DPFC } \\
\uparrow \text { activation in } \\
\quad \text { parietal cortex } \\
\quad \text { lateral temporal and polar regions }\end{array}$ \\
\hline $\begin{array}{l}\text { Drapier et al., } 2008 \\
{[31]}\end{array}$ & $\begin{array}{l}20 \mathrm{BD} I \\
\text { euthymic patients } \\
\text { mean age } \pm \text { DS: } \\
42.7 \pm 10.4\end{array}$ & $\begin{array}{l}20 \text { controls } \\
20 \text { first-degree } \\
\text { relatives }\end{array}$ & $1-, 2-, 3$-back & $1.5 \mathrm{~T}$ & $\begin{array}{l}\text { BD and relatives vs. controls: } \\
\downarrow \text { accuracy in bipolars vs. relatives and controls } \\
\text { (2- and 3-back); } \\
\uparrow \text { activation in left frontopolar cortex }\end{array}$ \\
\hline $\begin{array}{l}\text { Hamilton et al., } 2009 \\
\text { [33] }\end{array}$ & $\begin{array}{l}21 \mathrm{BD} I \\
\text { euthymic patients } \\
\text { mean age } \pm \text { DS: } \\
36.38 \pm 10.7\end{array}$ & $\begin{array}{l}38 \text { controls } \\
20 \text { schizophrenic } \\
\text { patients }\end{array}$ & $\begin{array}{l}\text { N-back } \\
\text { (on and off blocks) }\end{array}$ & $3.0 \mathrm{~T}$ & $\begin{array}{l}\text { BD vs. controls: } \\
\text { no differences in accuracy and reaction times; } \\
\downarrow \text { activation in } \\
\text { DLPFC } \\
\text { right primary visual cortex }\end{array}$ \\
\hline $\begin{array}{l}\text { Thermenos et al., } 2010 \\
{[24]}\end{array}$ & $\begin{array}{l}19 \mathrm{BD}(\mathrm{I}) \\
\text { euthymic patients } \\
\text { mean age } \pm \mathrm{DS}: \\
41.1 \pm 3.1\end{array}$ & $\begin{array}{l}19 \text { controls } \\
18 \text { first-degree } \\
\text { relatives }\end{array}$ & 2-back & $1.5 \mathrm{~T}$ & $\begin{array}{l}\text { BD and relatives vs. controls: } \\
\uparrow \text { activation in left anterior insula } \\
\text { BD vs. controls: } \\
\downarrow \text { accuracy, } \uparrow \text { reaction times (2-back) } \\
\downarrow \text { activation in left frontopolar cortex }\end{array}$ \\
\hline $\begin{array}{l}\text { Townsend et al., } 2010 \\
\text { [34] }\end{array}$ & $\begin{array}{l}42 \text { BD I patients } \\
(13 \text { manic, } \\
15 \text { euthymic and } \\
14 \text { depressed) } \\
\text { mean age } \\
\text { euthymics } \pm \text { DS: } \\
37 \pm 10\end{array}$ & 14 controls & 2-back & $3.0 \mathrm{~T}$ & $\begin{array}{l}\text { BD vs controls: } \\
\text { no differences in accuracy and reaction times; } \\
\downarrow \text { activation in } \\
\text { right DLPFC } \\
\text { posterior parietal cortex } \\
\uparrow \text { activation in } \\
\text { orbitofrontal cortex } \\
\text { temporal lobe structures }\end{array}$ \\
\hline $\begin{array}{l}\text { Jogia et al., } 2011 \\
\text { [35] }\end{array}$ & $\begin{array}{l}36 \text { BD I euthymic } \\
\text { patients } \\
\text { mean age } \pm \text { DS: } \\
42.5 \pm 10.6\end{array}$ & 37 controls & $\begin{array}{l}\text { 0-, 1-, 2-, 3-back, } \\
\text { Iowa Gambling task }\end{array}$ & $1.5 \mathrm{~T}$ & $\begin{array}{l}\text { BD vs. controls: } \\
\text { no differences in accuracy and reaction times; } \\
\downarrow \text { activation in the VL frontopolar cortex } \\
\uparrow \text { activation in } \\
\quad \text { right superior/middle temporal gyri } \\
\quad \text { insular cortex }\end{array}$ \\
\hline
\end{tabular}


tients had a lifetime diagnosis of BD I, and euthymia was defined as a Young Mania Rating Scale (YMRS) [26] total score of $\leq 5$ and a Hamilton Depression Rating Scale (HAM-D) [27] total score of $\leq 7$. Despite performing more poorly than the controls in terms of accuracy, patients did not differ from healthy volunteers with regard to reaction times. However, they showed enhanced activation across several brain regions, including the frontopolar PFC, anterior insula, basal ganglia, thalamus and temporal and posterior parietal cortex, traditionally implicated in WM circuits. These findings may not only reflect an increased effort during the patients' performance, but also the engagement of alternative cognitive strategies. By comparing medicated and unmedicated subjects, only temporal hyperactivation seemed to be associated with medication status.

In the same year, Monks et al. [22] recruited 12 euthymic bipolar males matched with 12 healthy volunteers. Euthymia was based on both HAM-D and YMRS scores. All subjects underwent 1.5-T fMRI with two separate paradigms, the 2-back and the Sternberg task [28], aimed at investigating the central executive and phonological loop, respectively - two components of WM, according to Baddeley's model of WM [29]. The authors found no significant between-group differences in the 2-back task performance (neither in accuracy nor in reaction times); however, BD patients showed a reduced response in the left frontal lobes, right middle temporal gyrus, cuneus/ precuneus and cerebellum while performing the 2-back task. Of note, patients exhibited a significant hyperactivation of the left precentral, right medial frontal and left supramarginal gyri during the 2-back task. Such findings might suggest an inefficient use of prefrontal circuits and the attempt to draw upon intact resources to support executive task performance. The authors proposed that these task-dependent abnormalities in the prefrontal areas may be associated with the central executive, rather than the phonological-loop functioning in euthymic BD patients.

In 2008, Frangou et al. [23] examined the functional integrity of WM circuits in 7 BD I patients who had achieved remission and remained on stable pharmacological treatment, and compared them with 7 healthy controls. They underwent 1.5-T fMRI, including the $\mathrm{N}$ back task (1-, 2- and 3-back), for the assessment of dorsal PFC (DPFC) functioning, and the Iowa Gambling task [30] to estimate the role of the ventral PFC (VPFC) in incentive decision-making. With regard to the N-back task, there were no between-groups differences in terms of performance. The predicted hyperactivation in the PFC of the BD patients could not be found and a DLPFC dysfunction seemed to be revealed only by increasing memory load, apparently because reliance on parietal areas might provide compensation at the behavioral level. During the Iowa Gambling task, accuracy and reaction times did not significantly differ between the 2 groups; the VPFC was found to be hypoactivated in BD patients in association with a lower response by the DPFC, while increased signal occurred in lateral and polar temporal regions. The authors suggested that alterations observed in PFC traits might impact negatively on VPFC-DPFC interaction, considered as the basis of WM processing.

Drapier et al. [31], using a similar paradigm (1-, 2- and 3-back) in a 1.5-T fMRI study, investigated the functional neural basis of WM impairment in a sample of 20 remitted BD patients, 20 unaffected first-degree relatives and 20 healthy controls. Assuming that first-degree relatives likely share some susceptibility genes that may lead to abnormalities in neurocognitive functioning [32], though on a milder level than those exhibited by patients, the authors tried to analyze the relationship between dysfunctional WM networks and genetic susceptibility to illness. Patients showed a poorer performance than the controls and the relatives on the 2- and 3-back condition, in terms of accuracy. A greater signal response was reported during the 2-back task in the frontal pole of relatives when compared with patients, who tended to activate, more intensively, the same region as in the 1-back condition. Such data led the authors to hypothesize that genetic predisposition to $\mathrm{BD}$ may be characterized by frontopolar hyperactivation related to a lower prefrontal functioning, found in patients and relatives.

In 2009, Hamilton et al. [33] focused on the functional correlates of WM networks in both schizophrenic and bipolar subjects. They recruited 21 euthymic BD I patients, 20 schizophrenics and 38 healthy volunteers. YMRS and HAM-D scores were used for defining euthymia. The 3-T fMRI paradigm consisted of a WM task including 'on' blocks, in which the subject had to indicate when a specific design had already appeared in a previous set, compared to a baseline condition ('off' blocks). Accuracy and reaction times did not differ significantly across groups. Activation in the PFC (left inferior frontal gyrus and left DLPFC) was significantly reduced in the schizophrenic patients, possibly indicating that they reached peak activation at a lower WM load or recruited non-DLPFC circuits during performance. The BD patients exhibited an activation of DLPFC on an average between the schizophrenics and the healthy individuals, not significantly different from the controls. They also
66

Neuropsychobiology 2013;68:63-70 DOI: $10.1159 / 000352011$
Cremaschi/Penzo/Palazzo/Dobrea/ Cristoffanini/Dell'Osso/Altamura 
showed hypoactivation of the occipital regions, including the right primary visual cortex, which may suggest dysfunction in the visuospatial component of WM.

In 2010, Thermenos et al. [24] analyzed patterns of neural activation in $19 \mathrm{BD}$ I patients, 18 unmedicated nonpsychotic first-degree relatives and 19 healthy subjects, undergoing 1.5-T fMRI with the 2-back task. As in the previous study, the addition of the latter comparison group was supposed to provide further information about the genetic vulnerability to the disorder, by revealing potential endophenotypes. Behavioral data of the 2-back condition showed a significantly lower accuracy and marginally longer reaction times in patients compared to controls. Intergroup differences in activation were reported in the insular, frontopolar, orbitofrontal and parietal cortices. In particular, both the BD patients and their relatives displayed a higher response in the left anterior insula, a region traditionally involved in emotion regulation. The relatives presented a greater activation in the left frontopolar cortex (in contrast with its decreased activity in patients), in the left orbitofrontal cortex (found to be hypoactivated in controls) and at the boundary of the right superior parietal lobe and postcentral gyrus. Frontopolar and orbitofrontal abnormalities were hypothesized to be associated with failure of emotional suppression, leading to hyperactivity of regions involved in emotional arousal during WM (such as the anterior insula) and interfering with the cognitive role of the frontopolar region in coordination and task learning. A similar trend of activation emerged in further analyses, conducted in a subgroup of 10 unmedicated $\mathrm{BD}$ patients, compared to the original control sample, in order to assess the influence of treatment.

In the same year, Townsend et al. [34] investigated potential fMRI ( $3 \mathrm{~T}$ ) abnormalities in a sample of $42 \mathrm{BD}$ I patients (13 manic, 15 euthymic and 14 depressed subjects) and 14 healthy comparison subjects, during a 2-back task. YMRS and HAM-D were used for defining euthymia. The additional evaluation of manic and depressed patients was aimed to clarify whether neurofunctional WM deficits and related severity might be state-dependent or persist beyond acute symptom remission. All subgroups of patients and controls had similar behavioral performance. In relation to within-group regions of activation, euthymic subjects showed an enhanced signal in right hemisphere areas, reporting a similar activation, in both controls and depressed BD patients, in the right DLPFC (with the recruitment of a more ventral portion of this area compared to the controls) and the right inferior frontal gyrus, along with an additional activation in

N-Back Task in Euthymic BD I Patients: A Review of fMRI the right superior frontal gyrus and right anterior cingulate. Furthermore, consistent with previous studies, between-group region of interest analyses documented a significant hypoactivation in the right DLPFC and posterior parietal cortex of all $\mathrm{BD}$ patients. Such findings seemed to be irrespective of mood state, suggesting the inability of patients to engage WM networks to the same extent as controls, even during euthymia, with no relevant differences in neural activation among phases of illness. Moreover, BD patients exhibited a higher activation of the orbitofrontal area, a region not typically involved in WM processing, and the engagement of temporal lobe structures, which may reflect a compensatory physiological effect.

More recently, Jogia et al. [35] tried to define patterns of functional brain abnormalities in 36 euthymic BD I patients and 37 healthy individuals, who underwent an fMRI scan while performing the Iowa Gambling Task and the N-back task. A significant effect of condition, but not of diagnosis, was observed in accuracy and reaction times during the N-back task. Focusing on WM processing, during the 3-back condition, the BD patients demonstrated an inefficient engagement within the VL frontopolar cortex, a region found to be overactivated in the 2-back task, possibly suggesting the inability of patients to recruit WM networks beyond a certain cognitive load. An enhanced signal in the right superior and middle temporal gyri was also reported in the 3-back task, as well as a significant insular overactivation, revealed by region of interest analyses. Such data seemed to support the existence of a coupled dysfunction, involving the inefficient recruitment of prefrontal cognitive circuits, along with a dysregulation among areas involved in emotional processing, as documented even in tasks not typically addressing emotional systems, such as the N-back task.

\section{Discussion}

Available evidence on fMRI studies, assessing WM in euthymic BD I patients, via the $\mathrm{N}$-back task, relies on 8 studies with a total of 145 patients, which represent an overall limited sample. Studies were conducted by means of 1.5-T $(\mathrm{n}=5)$ and 3-T $(\mathrm{n}=3) \mathrm{fMRI}$, and it may be worth mentioning that the most recently introduced scan machines allow more powerful magnetic fields $(\geq 7 \mathrm{~T})$. Nonetheless, studies using such technology have not yet been utilized in this specific field. Reported results can be distinguished on the basis of two levels: performance-related findings and neural activation data. 
With respect to behavioral data, most of the studies reported no significant differences in accuracy or reaction times, between $\mathrm{BD}$ patients and controls/other comparison groups. Nevertheless, $3 / 8$ studies found decreased accuracy and 1 found increased reaction times. It is worth emphasizing the importance of having similar task performance between groups, in order to minimize or avoid the potential influence of performance-related differences on neural engagement.

On the other hand, activation data seem to be consistent with the pattern of alteration described in several previous neuroimaging investigations on neurofunctional substrates of WM in $\mathrm{BD}$. According to such studies, the cortical components mostly implicated in WM included premotor cortex, dorsal cingulate/medial premotor cortex, DLPFC, VLPFC, posterior parietal and anterior cingulate cortex. Thus, the enhanced prefrontal activity of $\mathrm{BD}$ patients may be related to the recruitment of alternative circuits, with a compensatory effect aimed at supporting cognitive performance. In fact, WM seems to represent one of the main sources of dysfunction among BD patients, substantially affecting their everyday life-skills [36] and, thus, being at least partially responsible for their inability to regain a premorbid level of functioning [37, 38].

Available data also support the notion of a dysregulation in frontolimbic connections, traditionally implicated in the pathophysiology of $\mathrm{BD}$, as impairment of frontal networks may contribute to disinhibition of other temporal structures $[39,40]$.

The heterogeneity observed in the reviewed studies, in terms of neural activation, may be related to the small sample size and other potential confounding factors that impact on functional response, including concomitant pharmacological treatment [41] and the influence of different clinical variables [42].

With respect to medication effects, all the reviewed studies recruited patients on stable psychotropic medications, with 2 performing further analyses of unmedicated BD patients. Nonetheless, the limited size of these subgroups did not allow us to draw definitive conclusions. Data focused on the role of pharmacological treatment as a confounding factor are, in fact, still inconsistent, with some studies reporting no significant influence on performance $[43,44]$ and others suggesting a potential effect on cognitive processes, particularly with regard to lithium [21]. According to other authors, antipsychotic medications may have a detrimental impact on the cognitive functioning of BD I patients, whereas antidepressants, lithium and anticonvulsants do not seem to interfere with executive function [45]. Furthermore, a potential publi- cation bias due to studies with negative findings not being published cannot be ruled out. Therefore, follow-up studies comparing larger populations of medicated and unmedicated patients are to be encouraged, in order to extend previous investigations and to better understand the possible influence of medication on cognitive processes.

Other clinical variables potentially influencing cognitive functioning in general as well as WM in the revised studies, may include age at onset, duration of illness, psychiatric comorbidity, lifetime number of mood episodes, predominant polarity of episodes, type and duration of last episode and duration of euthymic phase [46]. Furthermore, a history of psychosis and alcohol/substance abuse may, in turn, account for part of the cognitive dysfunction [42]. Due to limited samples in reviewed studies, such correlation analyses were not performed. Providing clinical information of this kind may allow future metaanalyses.

As reported by $2 / 8$ studies considered $[24,31]$, the comparison with first-degree relatives of subjects with BD may help understanding of the influence of genetic liability to the disorder, enabling the detection of individuals at risk, by identifying potential endophenotypes of illness $[47,48]$. In fact, fMRI data on the relatives of BD patients, in terms of WM performance, are heterogeneous and preliminary: they include hyperactivation in the left frontal pole/VL gyrus [31], anterior insula and orbitofrontal cortex, probably associated with failed suppression of emotional arousal, which may interfere with cognitive performance [48].

Furthermore, the specificity of the afore-mentioned data needs to be taken into consideration. With this perspective, in fact, WM deficits have been widely documented also among schizophrenic patients, generally by means of hypoactivation of the PFC, even though more recent fMRI studies have reported either an equal or increased activation of DLPFC during WM performance [49]. For such reasons, further studies including samples of schizophrenic patients may clarify whether WM alterations are associated with common pathophysiological processes, a higher level of impairment in schizophrenia or whether they reflect the involvement of different subcomponents of WM in these two disorders [50, 51]. Currently, available data do not seem to support the hypothesis of a disorder specificity of neuroimaging findings, with different aspects, such as IQ, potentially accounting for neurocognitive differences [52].

Finally, it is worth stressing that all the reviewed studies examined patients with diagnosis of BD subtype I. For this reason, further investigation needs to be carried out
68

Neuropsychobiology 2013;68:63-70 DOI: $10.1159 / 000352011$
Cremaschi/Penzo/Palazzo/Dobrea/ Cristoffanini/Dell'Osso/Altamura 
in BD II patients, in order to shed light on the potential differences in patterns of WM alterations between these 2 subgroups of patients. Ultimately, a better understanding of the impact of cognitive impairment on psychosocial functioning during an euthymic phase - partly de- pending on WM deficits, as observed in this review - may contribute to providing more appropriate treatment strategies (e.g. cognitive rehabilitation) [53], at least in some groups of patients, in order to improve their functional outcome $[54,55]$.

\section{References}

1 Ketter TA: Diagnostic features, prevalence, and impact of bipolar disorder. J Clin Psychiatry 2010;71:e14.

-2 Altamura AC, Serati M, Albano A, Paoli RA, Glick ID, Dell'Osso B: An epidemiologic and clinical overview of medical and psychopathological comorbidities in major psychoses. Eur Arch Psychiatry Clin Neurosci 2011; 261:489-508.

3 Bora E, Yucel M, Pantelis C: Cognitive endophenotypes of bipolar disorder: a meta-analysis of neuropsychological deficits in euthymic patients and their first-degree relatives. J Affect Disord 2009;113:1-20.

4 Latalova K, Prasko J, Diveky T, Velartova H: Cognitive impairment in bipolar disorder. Biomed Pap Med Fac Univ Palacky Olomouc Czech Repub 2011;155:19-26.

5 Ferrier IN, Thompson JM: Cognitive impairment in bipolar affective disorder: implications for the bipolar diathesis. Br J Psychiatry 2002;180:293-295.

6 6 Martinez-Aran A, Vieta E, Colom F, Torrent $\mathrm{C}$, Sànchez-Moreno J, Reinares M, Benabarre A, Goikolea JM, Bruguè E, Daban C, Salamero M: Cognitive impairment in euthymic bipolar patients: implications for clinical and functional outcome. Bipolar Disord 2004;6: 224-232.

7 Torres IJ, Boudreau VG, Yatham LN: Neuropsychological functioning in euthymic bipolar disorder: a meta-analysis. Acta Psychiatr Scand Suppl 2007;434:17-26.

8 Mur M, Portella MJ, Martinez-Aran A, Pifarré J, Vieta E: Persistent neuropsychological deficit in euthymic bipolar patients: executive function as a core deficit. J Clin Psychiatry 2007;68:1078-1086.

-9 Judd L, Akiskal H, Schettler P, Endicott J, Leon AC, Solomon DA, Coryell W, Maser JD, Keller MB: Psychosocial disability in the course of bipolar I and II disorders: a prospective, comparative, longitudinal study. Arch Gen Psychiatry 2005;62:1322-1330.

10 Bearden CE, Woogen M, Glahn DC: Neurocognitive and neuroimaging predictors of clinical outcome in bipolar disorder. Curr Psychiatry Rep 2010;12:499-504.

11 Kurtz M, Gerraty RT: A meta-analytic investigation of neurocognitive deficits in bipolar illness: profile and effects of clinical state. Neuropsychology 2009;23:551-562.

12 Gruber O, Tost H, Henseler I, Schmael C, Scherk H, Ende G, Ruf M, Falkai P, Rietschel
M: Pathological amygdala activation during working memory performance: Evidence for a pathophysiological trait marker in bipolar affective disorder. Hum Brain Mapp 2010;31: 115-125.

13 MacQueen GM, Hajek T, Alda M: The phenotypes of bipolar disorder: relevance for genetic investigations. Mol Psychiatry 2005;10: 811-826.

14 Thompson JM, Gray JM, Hughes JH, Watson $S$, Young AH, Ferrier IN: Impaired working memory monitoring in euthymic bipolar patients. Bipolar Disord 2007:9:478-489.

15 Goldman-Rakic PS: Regional and cellular fractionation of working memory. Proc Natl Acad Sci USA 1996;93:13473-13480.

16 Glahn DC, Almasy L, Barguil M, Hare E, Peralta JM, Kent JW Jr, Dassori A, Contreras J, Pacheco A, Lanzagorta N, Nicolini H, Raventós $\mathrm{H}$, Escamilla MA: Neurocognitive endophenotypes for bipolar disorder identified in multiplex multigenerational families. Arch Gen Psychiatry 2010;67:168-177.

17 Gottesman II, Hanson DR: Human development: biological and genetic processes. Annu Rev Psychol 2005;56:263-286.

18 Hasler G, Drevets WC, Gould TD, Gottesman II, Manji HK: Toward constructing an endophenotype strategy for bipolar disorders. Biol Psychiatry 2006;60:93-105.

19 Karlsgodt KH, Bachman P, Winkler AM, Bearden CE, Glahn DC: Genetic influence on the working memory circuitry: behavior, structure, function and extensions to illness. Behav Brain Res 2011;225:610-622.

20 Matsuo K, Glahn DC, Peluso MA, Hatch JP, Monkul ES, Najt P, Sanches M, Zamarripa F, Li J, Lancaster JL, Fox PT, Gao JH, Soares JC: Prefrontal hyperactivation during working memory task in untreated individuals with major depressive disorder. Mol Psychiatry 2007;12:158-166.

21 Adler CM, Holland SK, Schmithorst V, Tuchfarber MJ, Strakowski SM: Changes in neuronal activation in patients with bipolar disorder during performance of a working memory task. Bipolar Disord 2004;6:540549.

22 Monks PJ, Thompson JM, Bullmore ET, Suckling J, Brammer MJ, Williams SC, Simmons A, Giles N, Lloyd AJ, Harrison CL, Seal M, Murray RM, Ferrier IN, Young AH, Curtis VA: A functional MRI study of working memory task in euthymic bipolar disorder: evidence for task-specific dysfunction. Bipolar Disord 2004;6:550-564.

23 Frangou S, Kington J, Raymont V, Shergill SS: Examining ventral and dorsal prefrontal function in bipolar disorder: a functional magnetic resonance imaging study. Eur Psychiatry 2008;23:300-308.

24 Thermenos HW, Goldstein JM, Milanovic SM, Whitfield-Gabrieli S, Makris N, Laviolette P, Koch JK, Faraone SV, Tsuang MT, Buka SL, Seidman LJ: An fMRI study of working memory in persons with bipolar disorder or at genetic risk for bipolar disorder. Am J Med Genet B Neuropsychiatr Genet 2010; 153B:120-131.

25 First MB, Spitzer RL, Gibbon M, Williams JBW: Structured Clinical Interview for DSMIV Axis I Disorders - Patient Edition (SCIDI/P, Version 2.0, 4/97 revision). New York, Biometrics Research Department New York State Psychiatric Institute, 1997.

26 Young RC, Biggs JT, Ziegler VE, Meyer DA: A rating scale for mania: reliability, validity and sensitivity. Br J Psychiatry 1978; 133:429435.

27 Hamilton A: A rating scale for depression. J Neurol Neurosurg Psychiatry 1960;23:56-61.

28 Sternberg S: The discovery of processing stages: extensions of Donder's method. Acta Psychol 1969;30:276-315.

29 Baddeley A: Working Memory. Oxford, Clarendon-Press, 1986

30 Bechara A, Damasio AR, Damasio H, Anderson SW: Insensitivity to future consequences following damage to human prefrontal cortex. Cognition 1994;50:7-15.

31 Drapier D, Surguladze S, Marshall N, Schulze K, Fern A, Hall MH, Walshe M, Murray RM, McDonald C: Genetic liability for bipolar disorder is characterized by excess frontal activation in response to a working memory task. Biol Psychiatry 2008;64:513-520.

32 Bora E, Vahip S, Akdeniz F, Ilerisoy $\mathrm{H}, \mathrm{Al}$ demir E, Alkan M: Executive and verbal working memory dysfunction in first-degree relatives of patients with bipolar disorder. Psychiatry Res 2008;161:318-324.

33 Hamilton LS, Altshuler LL, Townsend J, Bookheimer SY, Phillips OR, Fischer J, Woods RP, Mazziotta JC, Toga AW, Nuechterlein KH, Narr KL: Alterations in functional activation in euthymic bipolar disorder and schizophrenia during a working memory task. Hum Brain Mapp 2009;30:3958-3969. 
-34 Townsend J, Bookheimer SY, Foland-Ross LC, Sugar CA, Altshuler LL: fMRI abnormalities in dorsolateral prefrontal cortex during a working memory task in manic, euthymic and depressed bipolar subjects. Psychiatry Res 2010;182:22-29.

- 35 Jogia J, Dima D, Fumari V, Frangou S: Frontopolar cortical inefficiency may underpin reward and working memory dysfunction in bipolar disorder. World J Biol Psychiatry 2011; 13:605-615.

36 Robinson LJ, Ferrier IN: Evolution of cognitive impairment in bipolar disorder: a systematic review of cross-sectional evidence. Bipolar Disord 2006;8:103-116.

37 Jaeger J, Vieta E: Functional outcome and disability in bipolar disorders: ongoing research and future directions. Bipolar Disord 2007;9: $1-2$.

- 38 Sole B, Bonnin CM, Torrent C, MartinezAran A, Popovic D, Tabarés-Seisdedos R, Vieta E: Neurocognitive impairment across the bipolar spectrum. CNS Neurosci Ther 2012;18:194-200.

39 Strakowski S, Delbello M, Adler C: The functional neuroanatomy of bipolar disorder: a review of neuroimaging findings. Mol Psychiatry 2005; 10:105-116.

40 Savitz J, Drevets WC: Bipolar and major depressive disorder: neuroimaging the developmental-degenerative divide. Neurosci Biobehav Rev 2009;33:699-771.

-41 Balanza-Martinez V, Selva G, Martinez-Aran A, Prickaerts J, Salazar J, González-Pinto A, Vieta E, Tabarés-Seisdedos R: Neurocognition in bipolar disorders - a closer look at comorbidities and medications. Eur J Pharmacol 2010;626:87-96.
42 Phillips M, Vieta E: Identifying functional neuroimaging biomarkers of bipolar disorder: toward DSM-V. Schizophr Bull 2007;33: 893-904.

43 Hafeman DM, Chang KD, Garrett AS, Sanders EM, Phillips ML: Effects of medication on neuroimaging findings in bipolar disorder: an updated review. Bipolar Disord 2012;14:375410.

44 Phillips ML, Travis MJ, Fagiolini A, Kupfer DJ: Medication effects in neuroimaging studies of bipolar disorder. Am J Psychiatry 2008; 165:313-320.

45 Frangou S, Donaldson S, Hadjulis M, Landau S, Goldstein LH: The Maudsley Bipolar Disorder Project: executive dysfunction in bipolar disorder I and its clinical correlates. Biol Psychiatry 2005;58:859-864.

46 Robinson LJ, Thompson JM, Gallagher P, Goswami U, Young AH, Ferrier IN, Moore PB: A meta-analysis of cognitive deficits in euthymic patients with bipolar disorder. J Affect Disord 2006;93:105-115.

-47 Arts B, Jabben N, Krabbendam L, van Os J: Meta-analyses of cognitive functioning in euthymic bipolar patients and their first-degree relatives. Psychol Med 2008;38:771-785.

48 Thermenos HW, Makris N, Whitfield-Gabrieli S, Brown AB, Giuliano AJ, Lee EH, Faraone SV, Tsuang MT, Seidman LJ: A functional MRI study of working memory in adolescents and young adults at genetic risk for bipolar disorder: preliminary findings. Bipolar Disord 2011;13:272-286.
49 Manoach DS: Prefrontal cortex dysfunction during working memory performance in schizophrenia: reconciling discrepant findings. Schizophr Res 2003;60:285-298.

50 Schretlen DJ, Cascella NG, Meyer SM, Kingery LR, Testa SM, Munro CA, Pulver AE, Rivkin P, Rao VA, Diaz-Asper CM, Dickerson FB, Yolken RH, Pearlson GD: Neuropsychological functioning in bipolar disorder and schizophrenia. Biol Psychiatry 2007;62:179-186.

51 Sánchez-Morla EM, Barabash A, MartínezVizcaíno V, Tabarés-Seisdedos R, BalanzáMartínez V, Cabranes-Díaz JA, Baca-Baldomero E, Gómez JL: Comparative study of neurocognitive function in euthymic bipolar patients and stabilized schizophrenic patients. Psychiatry Res 2009;169:220-228.

52 Olvet DM, Stearns WH, McLaughlin D, Auther AM, Correll CU, Cornblatt BA: Comparing clinical and neurocognitive features of the schizophrenia prodrome to the bipolar prodrome. Schizophr Res 2010;123:59-63.

-53 Brissos S, Dias VV, Kapczinski F: Cognitive performance and quality of life in bipolar disorder. Can J Psychiatry 2008;53:517-524.

54 Simon GE, Bauer MS, Ludman EJ, Operskalski $\mathrm{BH}$, Unützer J: Mood symptoms, functional impairment, and disability in people with bipolar disorder: specific effects of mania and depression. J Clin Psychiatry 2007;68: 1237-1245.

55 Bearden CE, Shih VH, Green MF, Gitlin M, Sokolski KN, Levander E, Marusak S, Hammen C, Sugar CA, Altshuler LL: The impact of neurocognitive impairment on occupational recovery of clinically stable patients with bipolar disorder: a prospective study. Bipolar Disord 2011;13:3-33. 